\title{
D ispositivos da concorrência: como e em que medida a política antitruste faz mercados
}

Gustavo Onto*

Resumo

A política de defesa da concorrência brasileira busca garantir a concorrência nos mercados nacionais proibindo determinadas condutas empresariais e verificando os impactos de fusões e aquisições empresariais. Baseado em um trabalho etnográfico realizado no órgão responsável por essa política pública, o Conselho Administrativo de Defesa Econômica - o CADE -, este artigo demonstra como e em que medida esta forma de governo, entendida como um dispositivo, produz ou transforma mercados ao direcionar as ações de seus participantes. Aponta-se para três mecanismos pelos quais esse direcionamento ocorre: (i) a definição de limites legais das práticas empresariais; (ii) a mobilidade e circulação de artefatos; e (iii) a pedagogia implícita na ação governamental.

Palavras-chave: dispositivos, performatividade, mercados, política antitruste, CADE.

* Gustavo Onto é pesquisador do Núcleo de Pesquisas em Cultura e Economia (NuCEC) da Universidade Federal do Rio de Janeiro e pós-doutorando PNPD-Capes do Programa de Pós-graduação em Sociologia e Antropologia (PPGSA-IFCS) na mesma universidade. E-mail: gustavo.onto@gmail.com 


\section{Competition D evices: how and in what sense does antitrust policy makes markets}

\section{Abstract}

The Brazilian competition (defense) policy aims at guaranteeing competition in national markets by prohibiting certain business conducts and by reviewing corporate mergers and acquisitions. Based on an ethnographic work produced in the body responsible for this policy, the Administrative Council for Economic Defense - CADE -, this article demonstrates how and in what sense this form of government, understood as a device, produces and transforms markets by directing the actions of its participants. It points to three mechanisms by which this orientation occurs: (i) the definition of legal limits of economic practices; (ii) the mobility and circulation of artifacts; and (iii) the pedagogy implicit in governmental action.

Keywords: devices, performativity, markets, antitrust policy, CADE.

\section{Introdução}

"Mas então, o CADE realmente funciona?" Esta foi a pergunta que eu mais ouvi de amigos, conhecidos e familiares durante os anos em que estudei a política de defesa da concorrência brasileira e o órgão que a implementa. 0 verbo "funcionar", nesse caso, implicava saber se o Conselho Administrativo de Defesa Econômica tinha a capacidade de punir, reprimir e desautorizar condutas empresariais no país, fazendo-o com eficácia reconhecida e sem se deixar levar por influências políticas ou empresariais. Significava, no fundo, saber se o CADE garantia efetivamente a concorrência nos mercados do país. No início da minha pesquisa, em 
2008, eu respondia a pergunta com um convicto "não". O CADE certamente não funcionava. Fui estudar o órgão antitruste esperando encontrar fortes disputas ou controvérsias políticas entre os funcionários do governo e os agentes econômicos sobre decisões que afetariam as ações empresariais. Mas, na realidade, essas disputas eram praticamente inexistentes. 0 órgão antitruste, na prática, raramente condena práticas empresariais ou proíbe fusões e aquisições entre empresas. Aquilo que eu observava de início eram apenas reuniões, ligações telefônicas, apertos de mão e a produção imensa de documentos que pareciam não levar a lugar algum. Os funcionários do CADE, de um lado, e os advogados e os economistas das empresas, de outro, pareciam se conhecer de longa data, impossibilitando qualquer forma de relação mais divergente entre eles. O CADE parecia, naquele primeiro contato, uma tremenda farsa, existindo apenas para que acreditássemos que as condutas empresariais nos mercados são governadas por alguém.

Entretanto, como pude perceber ao longo da pesquisa, na pergunta sobre se o CADE "funciona" está implícito um certo entendimento sobre o que significa governar e, mais precisamente, governar os mercados. Nesse entendimento, o "Estado" e o "Mercado" são duas entidades distintas que nunca se misturam de fato. As misturas, quando existem, aparecem como impropriedades, poluidoras do sistema, produzindo aquilo que conhecemos como corrupção, lobbies, favorecimentos, negociações ou acordos, mal vistos pelos cidadãos e, muitas vezes, também pelos sistemas legais. Em geral, portanto, concebe-se a relação entre "Estado" e "Mercado" como se ambos conformassem instâncias autônomas e independentes, quase rivais, na organização da produção e circulação de produtos ou serviços, em que o final de um é o começo do outro. Governar apropriadamente os mercados, nesse caso, seria a capacidade do Estado se impor sobre os agentes de mercado conhecidos, sem que o "mercado" interferisse, mesmo que minimamente, na forma de governo. 
Na medida em que eu realizava a pesquisa, fui, aos poucos, questionando esse entendimento. Passei a observar que a política de defesa da concorrência só podia "funcionar", em certo sentido, por conta das várias formas de relações que atravessam o que seria a fronteira entre o Estado e o Mercado. Ao contrário do que havia interpretado anteriormente, são as pessoas, os conhecimentos ou saberes, as práticas e os artefatos que circulam entre essas duas esferas da vida social que explicam como se governa a concorrência. Neste artigo, demonstro, a partir de uma perspectiva etnográfica, como a política pública de defesa da concorrência constrói mercados competitivos - mais precisamente, impede os mercados de se tornarem menos competitivos - a partir de diferentes práticas governamentais, que implicam em diferentes formas de relação entre o órgão governamental e os sujeitos que são por ele administrados. Argumento que a "defesa da concorrência”, como política pública, pode ser pensada como um dispositivo que, embora não prescinda de mecanismos de punição, repressão ou desautorização de ações empresariais, utiliza-se de um conjunto mais amplo de práticas que permitem ao mesmo tempo conceber, conhecer e governar os mercados a partir de uma perspectiva concorrencial.

Atualmente, o CADE, com sede em Brasília, tem a atribuição legal de "zelar pela livre concorrência nos mercados". Isso, na prática, se resume a decidir e julgar dois tipos de processo administrativo. 0 primeiro tipo de processo são as solicitações para "fusões", "aquisições" e outras uniões contratuais, temporárias ou não, entre grandes empresas. Após uma investigação dos mercados e das empresas envolvidas nessas solicitações, o CADE pode autorizar estes chamados "atos de concentração" ou proibí-los, na hipótese da investigação ter indicado que a união empresarial venha a impor algum "risco", "dano" ou "prejuízo" à concorrência nos mercados. 0 segundo tipo cuida de investigações de "condutas empresariais anticompetitivas", sendo a mais conhecida delas a prática de "cartel". Geralmente abertos a partir de denúncias ou de indícios descobertos pelo próprio CADE, 
esses processos podem gerar pesadas multas administrativas para as empresas envolvidas, se ficar evidenciada a prática de condutas ilícitas. Voltando ao primeiro tipo de processo, a investigação é feita com o objetivo de prever "potenciais danos" que uma concentração pode gerar à concorrência de um mercado no futuro. No segundo caso, a investigação não é preventiva, mas, sim, retrospectiva, com vistas a compreender se uma determinada prática individual ou coordenada entre empresas gerou algum prejuízo à concorrência.

Durante um ano e meio de pesquisa nas dependências do órgão antitruste brasileiro, entre março de 2012 e agosto de 2013, período que coincidiu com a comemoração de 50 anos do CADE, procurei compreender como os profissionais daquela autarquia analisam e interpretam os casos que trabalham na prática; como eles fazem, no dia a dia, para decidir pela aprovação ou não de uma fusão ou pela condenação de uma empresa. Pude perceber, a partir do trabalho de campo, que essa decisão sempre depende da produção de um conhecimento sobre as características dos mercados e das empresas envolvidas num processo específico. Esse conhecimento produzido permite a avaliação dos impactos de concentrações empresariais nos mercados e a comprovação da ocorrência de condutas ilícitas. Ou seja, permite identificar a existência, ou não, de um possível "problema concorrencial”. São principalmente essas práticas de conhecimento, características da política de defesa concorrencial, que possuem o efeito de formatar mercados a partir de um ponto de vista concorrencial. Descrevo, nas seções abaixo, algumas dessas práticas.

A seguinte seção faz um breve resumo de teorias recentes utilizadas na sociologia e antropologia dos mercados, tendo em vista argumentar que o conceito de dispositivo é mais apropriado para tratar dos variados modos com que a política antitruste influencia a ação de participantes de mercados, transformando-os. A terceira, quarta e quinta seções discutem alguns dos mecanismos desse dispositivo: (i) a definição 
de limites legais das práticas empresariais; (ii) a mobilidade de artefatos de comunicação e de inscrição; e (iii) a pedagogia implícita na ação governamental ou o papel educativo do CADE. Por fim, concluo com algumas considerações sobre as diferentes relações que os mecanismos tornam evidentes, levando à impossibilidade de se avaliar a política antitruste dentro da dicotomia Estado-Mercado.

\section{Performatividade, dispositivos e arranjos mercantis}

Em 1998, o sociólogo francês Michel Callon editou uma coletânea que se tornaria referência nos estudos sociais da economia. Callon (1998), utilizando como exemplo a etnografia realizada pela antropóloga Marie-France Garcia (1986) sobre o mercado de morangos em Fontaines-en-Sologne, argumentou, conforme já haviam sugerido Karl Polanyi (1944), Louis Dumont (1977) ou Michel Foucault (2007), que o estudo do "econômico" não pode prescindir do estudo das formas de conhecimento que o define, mensura e formata. Baseando-se na noção de "performatividade" de John Austin (1962) e sua própria teoria do ator-rede (actor-network-theory), Callon (1998, p. 2) afirmou que a ciência econômica "performa" a economia: "Economics, in the broad sense of the term, performs, shapes and formats the economy, rather than observing how it functions". Sua proposta implicava entender como as teorias e modelos econômicos são fundamentais não somente como representações ou explicações do mundo econômico, mas, sim, como ferramentas que o performam ou o formatam por meio de práticas e políticas (Callon, 2007).

Influenciados por essa obra, muitos trabalhos de antropologia e sociologia da economia, inclusive aqueles que lidam com o governo da economia, passaram a descrever como o conhecimento econômico (teorias, formas de cálculo ou de mensuração), materialidades (documentos, softwares, computadores) e os profissionais da economia (Neiburg, 2007) - especialistas que lidam 
com questões econômicas, sobretudo os economistas - contribuem para a produção de objetos econômicos, tais como "mercados" (Mackenzie, Muniesa\& Siu, 2007; Pardo-Guerra, 2013), "preços estáveis" (Holmes, 2014; Neiburg, 2006) e a própria noção de uma "economia nacional” (Mitchell, 2002). Além disso, os estudos descrevem como são produzidas subjetividades econômicas: versões do indivíduo calculador e maximizador no mercado financeiro (Zaloom, 2006) ou "microempreendedores" em periferias urbanas (Elyachar, 2005). Os trabalhos demonstraram, dessa forma, como o conhecimento econômico e as práticas a ele associadas, governamentais ou não, constroem a realidade que supostamente, de acordo com sua própria concepção científica, apenas descreve ou explica.

Pode-se dizer que a abordagem performativa do econômico, que permeia esses e outros estudos, não pretende criticar, portanto, o modo como economistas descrevem a economia, mas, sim, a explicação a posteriori de cunho naturalista e realista que a ciência econômica daria para seus objetos de conhecimento (Muniesa, 2010). Segundo Bruno Latour (1993), referência importante nessa perspectiva, os cientistas - entre eles os economistas - se utilizariam de uma "língua bifurcada" (forked tongue) para dizer que a realidade não é construída quando tiverem acabado de construí-la. Dessa maneira, a abordagem performativa, tal como utilizada na sociologia e antropologia da economia, pressupõe uma diferença entre sua perspectiva sócio-antropológica e o conhecimento econômico. Os cientistas sociais, ou melhor, aqueles que se identificariam com a perspectiva performativa, assumiriam que constroem o conhecimento tanto quanto a realidade que descrevem. Os economistas, por outro lado, embora formatem ou performem a economia (por diversos meios, tais como pela formulação de políticas públicas, conselho políticos, publicação de artigos, entrevistas etc.), afirmam que somente descrevem, explicam ou desvendam o comportamento e as relações econômicas. Essa distinção entre as duas formas de conhecimento é o que produziria grande parte da relevância analítica e empírica dos 
estudos de performatividade, que apontam a fabricação daquilo que os profissionais da economia dizem ser dado ou natural.

Como mostrado acima, os mercados foram utilizados como exemplos da ação performativa do conhecimento econômico desde o início dessa linha de pesquisa. Mercados, como se sabe, são objetos epistêmicos típicos da ciência econômica, que estuda o funcionamento e as melhores formas de organizá-los tendo em vista atingir ideais de eficiência econômica nas trocas comerciais entre seus participantes. Entretanto, na medida em que novos estudos foram sendo realizados sobre a forma pela qual mercados são construídos e organizados, percebeu-se que a abordagem da performatividade não era capaz de lidar com a variedade de mecanismos que participam desse trabalho de market-making - tais como disputas profissionais, conflitos de poder, materialidades, tecnologias, artefatos e os usos diversos do conhecimento econômico por grupos distintos (ver Mackenzie, 2006 e Nieburg, 2006). Embora a abordagem performativa não descarte a necessidade do estudo de outros elementos que fazem ou constituem mercados para além das teorias, modelos ou saberes econômicos (Callon, 2007), os pesquisadores acabaram optando por utilizar expressões e conceitos mais amplos tais como "dispositivos de mercado" - market devices (Callon, Millo e Muniesa, 2007) - ou "arranjos mercantis" - agencements marchands (Callon, 2013) - para descrever os processos sociais, políticos, culturais e técnicos que conformam os mercados reais.

Os dispositivos de mercado são definidos nessa literatura como os "arranjos materiais e discursivos que intervêm na construção de mercados" (Muniesa, Millo e Callon, 2007, p.2). Essa definição dá importância ao papel dos não-humanos ou dos objetos na constituição dos mercados. Se os mercados são formados por pessoas e objetos, ou melhor, se eles só existem na interação entre pessoas e coisas, sejam essas coisas documentos, computadores, calculadoras, sejam prateleiras de supermercados, então 
estes elementos devem ser levados em conta nas descrições sobre a construção, o desenvolvimento e a transformação de mercados. Mais do que levados em conta na descrição, eles devem ser compreendidos como elementos que possuem agência ao estarem relacionados com outros, sejam estes outros pessoas, sejam coisas. Dispositivos de mercado são, portanto, arranjos sociotécnicos que produzem determinados modos de troca comercial que caracterizamos como mercantis e que estão sempre em permanente transformação.

Para Michel Foucault, em quem a literatura de estudos sociais sobre mercados se baseia para compreender esses arranjos, os dispostifs, devices ou apparatuses "não são simplesmente este ou esta medida política, este ou esta tecnologia de poder, e nem mesmo a generalidade obtida a partir de sua abstração, mas sim 'a rede [le réseau] que pode ser estabelecida entre esses elementos'” (Agamben, 2009, p.7). Fazendo uma genealogia do conceito de dispositivo em Foucault, o filósofo Giorgio Agamben o explica do seguinte modo: "I shall call an apparatus [dispositif] literally anything that has in some way a capacity to capture, orient, determine, intercept, model, control, or secure the gestures, behaviors, opinions, or discourses of living beings" (Agamben, 2009, p.14).

De acordo com a literatura recente sobre mercados nas ciências sociais, podemos dizer que a política de defesa da concorrência não somente performa mercados, no sentido de que ela auxilia na formatação de mercados a partir do conhecimento econômico, mas também faz parte de um enorme dispositivo que, em conjunto com outros arranjos sociotécnicos - outras políticas públicas, outras expertises como o marketing, outros profissionais e organizações -, produz os mercados com os quais lidamos no nosso dia a dia como consumidores de produtos ou serviços. Sabemos, pela variedade de agências, organizações, profissionais e saberes que movem a economia, que somente a política antitruste não seria suficiente para construir essas realidades 
que chamamos simplificadamente de mercados. Contudo, essa política pública age, no sentido forte de conceber e transformar, sobre os mercados com relação a um aspecto específico que é sua concorrência.

A política antitruste pode, portanto, ser concebida como um dispositivo da concorrência atuando sobre mercados no sentido dado por Agamben, pois ela tem a capacidade de orientar, determinar e controlar certos comportamentos, opiniões e discursos de agentes econômicos visando torná-los mais próximos de um ideal concorrencial. Essa definição ampla da noção de dispositivo é interessante tendo em vista os variados mecanismos por meio do qual a política pública procura alterar esses sujeitos de direito, essas entidades jurídicas e econômicas - pessoas jurídicas ou empresas - que ela administra, transformando assim os próprios mercados do qual estes sujeitos fazem parte. As próximas seções ilustram o funcionamento de três mecanismos desse dispositivo da concorrência.

\section{$2 \mathrm{D}$ ecisões finais}

O modo mais evidente de como a política de defesa da concorrência faz ou formata mercados é claramente por meio das decisões finais do Tribunal do órgão governamental, o CADE. O CADE decide algumas dezenas de casos por mês relativos a condutas anticompetitivas ou concentrações empresariais. Essas decisões escritas e proferidas em julgamento formatam mercados, pois impõem limites à ação de uma ou mais empresas. Como as decisões de órgãos antitruste são facilmente conhecidas por pesquisadores, este mecanismo de performação dos mercados tem sido amplamente documentado e descrito por sociólogos, geógrafos e cientistas políticos. Brett Christophers afirma em artigo recente (2015) que a política ou a lei de defesa da concorrência constitui um exemplo claro de como se dá a "performatividade" da teoria econômica. Analisando os impactos das decisões de alguns casos específicos da Competition Commis- 
sion, o órgão antitruste do Reino Unido, o autor argumenta que as definições de mercado teriam contribuído para a criação de fronteiras ou barreiras entre mercados "reais", pois levaram a proibições de certas práticas empresariais" ${ }^{1}$ :

The drawing of conceptual boundaries is active and material, leading to the redrawing of lived boundaries - boundaries between what is and is not legal in actual economic practice, between those on the wrong and right sides of legality (Christophers, 2015, p. 12).

Assim, segundo o autor, o modo como a autoridade concebe um mercado - definindo qual sua área geográfica, que produtos ou serviços fazem parte dele e quem são seus participantes ou concorrentes - performa, transforma ou modifica mercados, pois impõe limites à ação empresarial, com base em teorias sobre o melhor funcionamento dos mercados desenvolvidas em escolas de economia norte-americanas. 0 argumento de Christophers já havia sido ensaiado na própria introdução já mencionada de Michel Callon em 1998. Para este autor, a legislação seria um dos elementos essenciais dos dispositivos que participam na construção de mercados. Na introdução seminal ao livro que editou, Callon (1998, p. 28) afirma:

Among those mediators which bind economics to economy while constituting each as an independent entity, law, together with accounting metrology and marketing management, is well situated. Of course it provides a powerful tool for framing, or more precisely for enacting, calculative agencies. But what we wish to emphasize here is that it is an essential link, an irreplaceable coupling device between theoretical work and economic practices, for it organizes real experiments.

1 Türem (2011) e Dobbin e Dowd (2000), utilizando outras referências teóricas, têm argumentos semelhantes sobre o modo como as políticas antitruste turca e norte-americana, respectivamente, performam mercados. 
O sociólogo ainda menciona explicitamente o tema que nos interessa neste artigo: "a lei de concorrência [...] obviamente promove a calculabilidade das decisões ao enquadrar ações e relações autorizadas" (Callon, 1998, p. 54). De fato, concordando com esses estudos, as decisões tomadas pelo órgão antitruste, baseadas na lei concorrencial, performam mercados, pois definem limites que serão levados em consideração pelas empresas nas suas decisões futuras, alterando o modo de funcionamento dos mercados. As definições de um "mercado relevante geográfico de $10 \mathrm{~km}$ " e de um "mercado relevante de produto de oncologia" num voto, por exemplo, podem ter impactos sobre as relações de concorrência entre as empresas requerentes, seus concorrentes e consumidores em várias localidades, produzindo novos mercados e transformando aqueles já existentes.

Num artigo de 2016 (Onto, 2016a), demonstrei como os analistas do CADE procederam na análise da aquisição da empresa aérea da Webjet pela Gol. De acordo com a análise empreendida no CADE, a união das duas empresas poderia resultar em uma concentração excessiva das rotas aéreas no aeroporto Santos-Dumont no Rio de Janeiro, criando poucas opções para os consumidores que optam por voar a partir deste aeroporto. A solução preferida pelo conselheiro foi exigir que a nova empresa, resultante da união das duas, ofertasse voos com uma alta frequência nesse aeroporto, impedindo uma possível escassez de voos e garantindo preços mais baixos no mercado. Dessa forma, podemos ver com clareza o modo como uma decisão antitruste estabelece e limita comportamentos para as empresas de um determinado mercado.

Esse mecanismo pelo qual o órgão e a política antitruste governam a concorrência nos mercados talvez seja mais facilmente visível. Contudo, ao afirmar que as decisões constroem limites de ações empresariais e, por isto, performam mercados concretos, estamos argumentando apenas com base nos efeitos conhecidos da política pública. Existem outros modos menos explícitos de 
funcionamento desse dispositivo da concorrência que tem a ver com as próprias práticas de conhecimento envolvidas na análise antitruste, como o envio e o recebimento de documentos e os preenchimentos de tabelas e anexos.

\section{A mobilidade e circulação dos artef atos}

Cada pedido de concentração empresarial, ou cada denúncia relevante de prática anticompetitiva em um mercado, dá origem a um processo administrativo que é instruído pelo CADE. A análise ou investigação dos requerimentos e denúncias desses processos exige uma produção extensa de documentos, tabelas e gráficos que permitem aos analistas, assessores e estagiários chegar a uma conclusão sobre um caso, resolvendo se decidem por condenar uma empresa ou autorizar uma aquisição, por exemplo. Os documentos produzidos por assessores em geral contêm perguntas e tabelas que devem ser respondidas e preenchidas pelas empresas participantes de um mercado, estejam elas envolvidas ou não na conduta ou na concentração sob análise. Ao coletar informações de diversos agentes em um mercado, o órgão antitruste consegue obter uma noção melhor do modo como opera um setor ou indústria e como se comportam as empresas.

Essas práticas de produção, envio e circulação de documentos entre o órgão regulador e os administrados consiste num segundo importante mecanismo pelo qual os mercados e seus agentes são orientados ou guiados em direção a um ideal de comportamento mais competitivo. Essas práticas de documentação e os artefatos de conhecimento que fazem parte delas (como tabelas, mapas, gráficos, imagens) produzem uma coordenação de perspectivas e de entendimentos sobre as relações de mercado, que são compartilhadas e negociadas entre empresas, seus representantes e pelos funcionários do CADE. Os documentos circulados para além dos limites do órgão antitruste, portanto, formatam e padronizam representações econômicas. 
Por exemplo, o envio de tabelas por meio de ofícios é comum nos procedimentos de instrução processual do CADE. 0 recebimento de dados na forma de tabelas facilita o trabalho do assessor, pois padroniza e fixa o sentido de todas as categorias e informações de que ele precisa para analisar o processo, tornando-as comparáveis. Para muitos, mais importante que a precisão da informação dada é a necessidade de que todas as empresas oficiadas enviem informações que possam ser comparadas e organizadas conjuntamente. Sem isso, não há como fazer a análise de um processo. Por isso, assessores costumam passar um tempo relativamente extenso refletindo sobre o melhor modo de criar tabelas - quais categorias as tabelas devem incluir e como formular perguntas que não contenham ambiguidades. A forma com que os dados são enviados para o CADE acaba sendo tão importante quanto os significados dessas informações. Como vem afirmando Annelise Riles em uma série de trabalhos $(2006,2010,2011)$, as tabelas impõem um modo de agência diferente àqueles que as recebem, pois exigem, principalmente, não sua leitura ou interpretação, mas apenas seu preenchimento (form-filling).

As tabelas também são importantes porque facilitam as respostas por parte de pessoas com diferentes formações que podem ser obrigadas a responder a elas. Embora grande parte das empresas oficiadas tenha representantes legais com formação em direito da concorrência e que irão responder aos ofícios, muitas delas, empresas pequenas ou que não participam diretamente na operação analisada, não irão contratar advogados para fazê-lo. 0 próprio gerente da unidade provavelmente irá preencher as tabelas e, por isto, elas devem ser compreensíveis, sem conceitos econômicos ou jurídicos muito esotéricos.

Na antropologia da economia, alguns trabalhos vêm apontando o modo como práticas de documentação e suas materialidades são imprescindíveis à construção de objetos, sujeitos ou organizações econômicas como os mercados. As pesquisas descrevem, 
por exemplo, como contratos de securitização produzem o mercado de transações futuras de ações (Riles, 2010, 2011), como atas de reuniões e relatórios técnicos dos bancos centrais produzem mercados (Holmes, 2014), como questionários de qualidade produzem serviços e consumidores (Callon, 2002), como tabelas com valores estatísticos produzem preços (Mackenzie, 2009); cartões (scorecards) que produzem o "risco de crédito" do consumidor (Poon, 2007) ou títulos de propriedade que produzem “capital” (Mitchell, 2005).

Na etnografia de Annelise Riles $(2010,2011)$ sobre os aspectos legais das transações no mercado financeiro japonês, a antropóloga descreve como os contratos de securitização de compras e vendas de ações, que aparentemente consistem em meros detalhes técnicos, marginais ao mercado, são essenciais para toda a existência de produtos financeiros e sua comercialização. Segundo Riles, esses documentos jurídicos que garantem um seguro monetário no caso de uma das partes não cumprir seu acordo financeiro:

são tecnologias cruciais [...] para formatar e padronizar o mercado por causa de sua habilidade única de viajar através de fronteiras - fronteiras culturais, formas de expertise, instituições, distâncias físicas pela virtude de sua forma material ou estética. [...] [a] padronização, nesse sentido, é tanto um projeto conceitual quanto um projeto material" (Riles, 2011, p. 59).

Nesse mesmo sentido, no CADE, os ofícios, as petições e seus anexos contribuem para performar ou fazer mercados não apenas por meio das definições que eles carregam em seu texto, mas também pela coordenação de perspectivas e atividades que eles promovem ao serem circulados (Hull, 2012). A análise antitruste é feita pela circulação e produção de documentos, que é acompanhada da circulação de pessoas, representantes das partes e consultores econômicos que vão ao CADE entregar petições, pareceres ou se reunir com assessores e conselheiros para ex- 
plicar seus argumentos, tirar dúvidas ou tentar entender a posição dos funcionários do governo. Os documentos que circulam e são produzidos entre burocracias, escritórios de advocacia e empresas formatam e padronizam representações do mercado, formas de conhecimento sobre setores, empresas e consumidores, construindo entendimentos compartilhados sobre estes objetos e sujeitos. É principalmente por meio das práticas que envolvem a produção, a circulação, a leitura e o preenchimento de documentos que os princípios teóricos sobre o funcionamento dos mercados, adotados pela política antitruste, contribuem para "ajustar" a realidade à teoria (Callon, 2007).

\section{0 papel educativo da política}

Podemos dizer que se os funcionários do CADE não refletem tanto sobre o papel das práticas de conhecimento na formatação de mercados, mas isto não quer dizer que eles não tenham plena consciência do papel da política pública como um dispositivo da concorrência, ou seja, como um mecanismo de construção de comportamentos e ideais concorrenciais nos mercados. Isso fica evidente nas narrativas sobre o "papel educativo" do CADE, surgidas desde os anos 1990 nos documentos oficiais do órgão antitruste ${ }^{2}$.

0 primeiro Relatório Anual do CADE, publicado em 1996, foi produzido com o objetivo de "dar maior transparência para a sociedade sobre a atividade do órgão antitruste", proporcionando uma síntese dos processos julgados, das decisões administrativas tomadas, além de um conjunto de estatísticas sobre a atividade do órgão no ano. 0 documento dividia-se em três partes, que corresponderiam às três funções do órgão antitruste: (i) o combate às infrações de ordem econômica, ou o papel repressivo; (ii) o controle de atos de concentração, ou o papel preventivo; e (iii) a

2 Para uma análise mais detalhada desse aspecto da política de defesa da concorrência, ver Onto (2016b). 
promoção da livre concorrência, ou o papel educativo. Um trecho do Relatório de 1996 define o propósito do "papel educativo":

\begin{abstract}
Dado o longo período de atuação de um Estado interventor, e de fechamento do país, a concorrência ainda se constitui um elo estranho às relações econômicas e seus agentes. Sendo assim, é crucial que o CADE se torne um instrumento de difusão da cultura da concorrência. Nesse sentido, o CADE deve ter três papéis complementares e interdependentes: educativo, preventivo e repressor. 0 papel educativo representa a própria difusão da cultura da concorrência no país. Torna-se, assim, uma obrigação do CADE divulgar e demonstrar analiticamente a importância da defesa da concorrência de forma a prover um maior grau de intimidade da sociedade com seus elementos constituintes. No exercício de seu papel preventivo, basicamente regula as operações que venham a implicar aumento excessivo do poder de mercado e que, consequentemente, tornem provável a ocorrência de abusos. Já o papel repressor é o mais óbvio, sendo aquele pelo qual o público naturalmente reconhece a função de órgãos como o CADE. Ressalte-se que tanto o papel preventivo como, principalmente, o papel repressor são fundamentais para o cumprimento do papel mais importante do CADE, que é o educativo. De fato, o principal efeito da repressão e da prevenção é, sem dúvida, a sinalização que o mercado obtém a respeito de que tipo de ações e condutas são toleradas ou não, conforme o critério de razoabilidade consagrado na jurisprudência moderna do direito econômico (CADE, Relatório Anual, 1996, p. 25, grifos meus).
\end{abstract}

O papel educativo do CADE era entendido como algo necessário, considerando-se a trajetória histórica das formas de relação empresarial brasileira. Segundo Considera e Corrêa (2002, p. 3), "o clima ideológico parece não ter favorecido a concorrência como a regra do jogo econômico; o setor privado não a entende como o cerne da atividade econômica [...]. Pelo contrário, o clima ideológico parece ter favorecido a 'negociação' entre firmas”. Para esses economistas, este "clima ideológico" derivava da herança do período de política econômica mais desenvolvimentista ou 
intervencionista. A ex-presidente do conselho Elizabeth Farina explica (comunicação pessoal) que existia na economia brasileira uma espécie de "cultura de planilha de custos". Essa cultura refletia-se numa prática empresarial comum desde o período militar, em que planilhas com os custos das firmas eram repassadas de uma a outra empresa para que todas pudessem comparar seus preços e organizar sua produção coordenadamente (Onto, 2016b). Essa prática de cartel não era entendida como ilegal ou imprópria pelas empresas. Por isso, para a ex-conselheira Lúcia Helena Salgado:

as políticas de defesa da concorrência têm um importante papel a desempenhar, na medida em que venham, por um lado, a evitar que as barreiras levantadas pelo governo sejam repostas por aqueles que detêm o poder econômico e, por outro lado, reeducar o mercado - leia-se aí produtores e consumidores - de acordo com as regras de intensa competição que hoje orientam as transações internacionais (Salgado, 1992, p. 30).

O papel educativo do CADE caracterizou-se por algumas medidas bastante práticas. Entre 1996 e 2008, o conselho adotou políticas "educativas" específicas, nos moldes das medidas adotadas pelo órgão antitruste norte-americano, abrangendo iniciativas que vão desde uma campanha intensiva na mídia até a participação em grupos de trabalho com diversos órgãos governamentais (Considera \& Araújo, 2002). As principais políticas de advocacia da concorrência desse período foram a criação de fórum permanente de políticas de concorrência, a criação de um website, a reedição da revista de direito econômico e a criação de um programa de intercâmbio (Onto, 2016b).

O papel educacional explicitado nos relatórios anuais do CADE demonstra como a política antitruste, pelo menos aquela promovida a partir dos anos 1990, tinha a intenção clara de servir como um dispositivo da concorrência, que não apenas se utiliza 
de mecanismos punitivos ou repressivos, mas também de práticas pedagógicas para realizar seus objetivos. A construção de mercados em que comportamentos competitivos prevalecem é uma aspiração daqueles profissionais responsáveis pela implementação da política, juristas e economistas que assumiram, a partir dos anos 1990, cargos de conselheiros e presidentes do órgão antitruste. Os profissionais do CADE sabem que suas decisões ou julgamentos podem alterar ou transformar essa realidade.

\section{Considerações Finais}

Este artigo demonstrou certos mecanismos que tornam a política de defesa da concorrência um dispositivo da concorrência, ou seja, uma rede de práticas, narrativas e artefatos que orientam, conduzem e determinam comportamentos, discursos e ideologias nos mercados, visando estabelecer um ideal de concorrência que é simultaneamente legal, moral e econômico. Porém, se o órgão de defesa da concorrência influencia na constituição e no funcionamento de mercados, como um dispositivo de mercado (Muniesa, Millo e Callon, 2007), ele o faz somente no que diz respeito aos aspectos concorrenciais. E além de limitado a esse aspecto, o órgão também só atua efetivamente como um dispositivo da concorrência nos mercados que estão sob análise nos processos administrativos que instrui regularmente. Essa ponderação é necessária para que não se imagine que o órgão antitruste possui automaticamente algum tipo de influência direta em todos os mercados nacionais e em todos os seus aspectos. Os mercados, como argumentado na literatura exposta no início do artigo, estão sempre sendo transformados por agenciamentos diversos que os levam a uma direção mais ou menos próxima daquela desejada pelo órgão antitruste.

Mais importante do que compreender os limites da ação governamental antitruste com relação aos mercados é entender as diferentes formas pela qual a política pública implementa seus 
objetivos. Algumas dessas formas são mais óbvias ou explícitas para os responsáveis pela política pública e outras são menos visíveis, sendo mais apreensíveis de um ponto de vista etnográfico. Como disse no início deste artigo, o governo, ou a defesa da concorrência, implica em diferentes formas de relações entre o CADE e os agentes de mercado, que se tornam evidentes por meio da descrição das práticas de conhecimento do órgão antitruste. São essas práticas que são capazes de explicar como a concorrência é defendida ou governada, não somente porque estas práticas levam a uma decisão ou julgamento final pelo CADE, resultando em punições ou restrições de práticas empresariais, mas, sim, porque elas, ao serem performatizadas, constroem, disseminam ou formatam entendimentos, concepções e realidades econômicas.

Tratar a política de defesa da concorrência como um dispositivo é produtivo, pois abre as possibilidades de compreensão de como e em que medida a política antitruste faz mercados. 0 efeito de uma decisão final do órgão, as práticas de conhecimento com a mobilidade ou circulação de artefatos e as medidas educativas, cada uma de uma maneira, produzem e transformam o comportamento de agentes econômicos e, portanto, do mercado do qual eles fazem parte. Cada um desses mecanismos também implica em um modo distinto de relação entre o Estado e seus administrados, que impede uma avaliação rápida sobre o papel do CADE na defesa da concorrência. Mesmo que as decisões do órgão antitruste não costumem proibir um número grande de fusões e aquisições empresariais, isto não quer dizer que o CADE não tenha um papel na formatação destes mercados pelos mecanismos descritos acima.

\section{Ref erências}

AGAMBEN, G. What is an Apparatus? Stanford: Stanford University Press, 2009. AUSTIN, J. L. How to do things with words. Cambridge: Harvard University Press, 1962. 
CADE. Relatório Anual 1996. Brasília: Conselho Administrativo de Defesa Econômica, 1996.

CALLON, M. Introduction: The embeddedness of economic markets in economics. In: __ (ed.). The Laws of the Markets. Oxford; Malden, MA: Blackwell Publishers, 1998. p. 1-57.

CALLON, M. Writing and (Re)Writing Devices as Tools for Managing Complexity. In: MOL, A. \& LAW, J. Complexities: Social Studies of Knowledge Practices. Durham: Duke University Press, 2002.

CALLON, M. What does it mean to say that economics is performative? In: MACKENZIE, D; MUNIESA, F \& SIU, L (eds.). Do economists make markets? On the performativity of economics. Princeton, NJ: Princeton University Press, 2007.

CALLON, M. Qu'est-ce qu'un agencement marchand? In: CALLON et al. (eds.) Sociologie des agencements marchands: textes choisis. Paris: Presses de Mines, 2013, p. 325-440.

CALLON, M.; MUNIESA, F. \& MILLO, Y. (eds.). Market devices. London: Blackwell Publishing, 2007.

CHRISTOPHERS, B. The law's markets: Envisioning and effecting the boundaries of competition. Journal of Cultural Economy, v. 8, n. 2, p. 12543, 2015.

CONSIDERA, C; ARAÚJO, M.T. Competition Advocacy in Brazil - Recent Developments. SEAE, Documentos de Trabalho, Nov. 2002.

DOBBIN, F; DOWD, T. How Policy Shapes Competition: Early Railroad Foundings in Massachusetts. Administrative Science Quarterly, v. 42, n.3, p. 50129, 1997.

DUMONT, L. Homo aequalis I: Genèse e épanouissement de l'idéologie économique. Paris: Éditions Gallimard, 1977.

ELYACHAR, J. Markets of Dispossession: NGOs, Economic Development, and the State in Cairo. Durham: Duke University Press, 2005.

FOUCAULT, M. The Birth of Biopolitics: Lectures at the Collège de France (1978-1979). New York: Palgrave Macmillan, 2007.

GARCIA, Marie-France. La construction sociale d'un marché parfait: Le marché au cadran de Fontaines-en-Sologne. Actes de la Recherche en Sciences Sociales, n. 65, p. 2-13, 1986.

HOLMES, D. Economy of Words: Communicative Imperatives in Central Banks. Chicago: Chicago University Press, 2014. 
HULL, M. Documents and Bureaucracy. Annual Review of Anthropology,v. 41, p. 251-67, 2012.

LATOUR, B. We have never been modern. Cambridge: Harvard University Press, 1993.

MACKENZIE, D. An Engine, Not a Camera: How Financial Models Shape Markets. Cambridge: The MIT Press, 2006.

MACKENZIE, D. Material markets: how economic agents are constructed. Oxford: Oxford University Press, 2009.

MACKENZIE, D.; MUNIESA, F. \& SIU, L. (eds.). How economists make markets: on the performativity of economics. Princeton, NJ: Princeton University Press, 2007.

MITCHELL, T. Rule of Experts: Egypt, Techno-Politics, Modernity. Berkeley: University of California Press, 2002.

MITCHELL, T. The work of Economics: how a discipline makes its world. European Journal of Sociology, v. 46, n. 02, p. 297-320, August 2005.

MUNIESA, F. The problem with economics: naturalism, critique and performativity. CSI Working Papers Series, $n^{\circ}$ 020, 2010.

MUNIESA, F., MILLO, Y. e CALLON, M. An introduction to market devices. In: CALLON, M.; MUNIESA, F. \& MILLO, Y. (eds.). Market devices. London: Blackwell Publishing, 2007.

NEIBURG, F. Inflation: Economists and Economic Cultures in Brazil and Argentina. Comparative Studies in Society and History, v. 46, n. 3, p. 60433, 2006.

NEIBURG, F. As moedas doentes, os números públicos e a antropologia do dinheiro. Mana, v. 13, n. 1, 2007.

ONTO, G. O mercado como um contexto: delimitando o problema concorrencial de uma aquisição empresarial. Horizontes Antropológicos, v. 45, n. 22, p. 155-84, 2016a.

ONTO, G., Regulação como transformação cultural: o 'papel educacional' da política concorrencial brasileira. Direito \& Práxis, v. 7, n. 16, p. 690-715, 2016b.

PARDO-GUERRA, J. P. Making markets: infrastructures, engineers and the moral technologies of finance, Manuscrito, 2013.

POLANYI, K. The great transformation: the political and economic origins of our time. New York, Toronto: Farrar \& Rinehart, 1944. 
POON, M. Scorecards as devices for consumer credit: the case of Fair, Isaac \& Company Incorporated. In: CALLON, M.; MUNIESA, F. \& MILLO, Y. (eds.). Market devices. London: Blackwell Publishing, 2007. p. 284-306.

RILES, A. Introduction: In Response. In: RILES, Annelise (ed.). Documents: Artifacts of Modern Knowledge. Ann Arbor: University of Michican Press, 2006. p. 1-38.

RILES, A. Collateral expertise: legal knowledge in the global financial markets. Current Anthropology, v. 51, n. 6, p. 795-818, 2010.

RILES, A. Collateral knowledge: legal reasoning in the global financial markets. Chicago: The University of Chicago Press, 2011.

SALGADO, L. H. As Políticas de Concorrência (ou Antitruste): Um Panorama da Experiência Mundial e sua Atualidade para o Brasil. Texto para Discussão n. 264, IPEA, jun. 1992.

TÜREM, Z. U. Engineering neoliberalism in the global South: politics of competition and regulatory reform in Turkey. PhD Dissertation, Institute for Law and Society, New York University, 2010.

ZALOOM, C. Out of the pits: traders and technology from Chicago to London. Chicago: The University of Chicago Press, 2006.

Recebido em 24/02/2017

Aprovado em 31/05/2017 
